\title{
In Memoriam of Professor Hitoshi Emi
}

\author{
Kikuo Okuyama1, Yoshio Otani², Takafumi Seto ${ }^{3}$
}

${ }^{1}$ Professor Emeritus of Hiroshima University

${ }^{2}$ Professor Emeritus of Kanazawa University

${ }^{3}$ Professor of Kanazawa University

On April 6, 2020, Prof. Emi passed away at the age of 82. He graduated in 1961 from Kyoto University, and continued his studies at the Graduate School of Kyoto University. In 1969 until his retirement in 2003 he worked at Kanazawa University. He started as an associate professor and obtained his doctoral degree from Kyoto University in 1969 . He became a full professor of Kanazawa University in 1977 and was the dean of engineering at Kanazawa University from 1995 to 1997.

At Kyoto University, he carried out his research, under the supervision of Prof. Naoya Yoshioka, where he wrote his dissertation "Air filtration with fibrous filters". The dissertation was about single fiber collection efficiency and its experimental verification (Chapter 1), mechanical collection efficiency of fibrous filters (Chapter 2), influence of electrostatic force on fibrous filtration (Chapter 3), effect of gravity on single fiber collection efficiency (Chapter 4), dust loading effect of fibrous filters (Chapter 5), and performance of rotating packed bed scrubber (Chapter 6). The research achievements of his Ph.D. course became the basis of air cleaning and dust collection in various industries in Japan.

He was the first person to develop the filtration theory based on single fiber collection efficiency in the world. He conducted detailed particle trajectory calculations with a computer in the era when computers were not as well developed and revealed the effects of various mechanical collection mechanisms on collection efficiency, which was later quoted in "Aerosol Science" written by Prof. C.N. Davies (Academic Press, 1966). The design of HEPA filters that has been used for industrial and biological clean rooms is based upon his single fiber collection efficiency theory.

In 1978 Prof. Chiu-sen Wang invited Prof. Emi as a visiting professor to Syracuse University New York where he worked with Prof. Chiu-Sen Wang and Prof. Chi Tien on dust loading characteristics of wire screen. It was while he was in Syracuse that he met and became lifelong friends with Prof. Eichi Negishi, the winner of the Nobel Prize in Chemistry 2010, who was also at Syracuse University at that time. We were told by Prof. Emi that he helped him pack and saw him off on his departure from Syracuse to West Lafayette, Indiana, where Prof. Negishi was heading and received the Nobel Prize at Purdue University.

One year after the establishment of the American Association for Aerosol Research (AAAR), Prof. Emi and

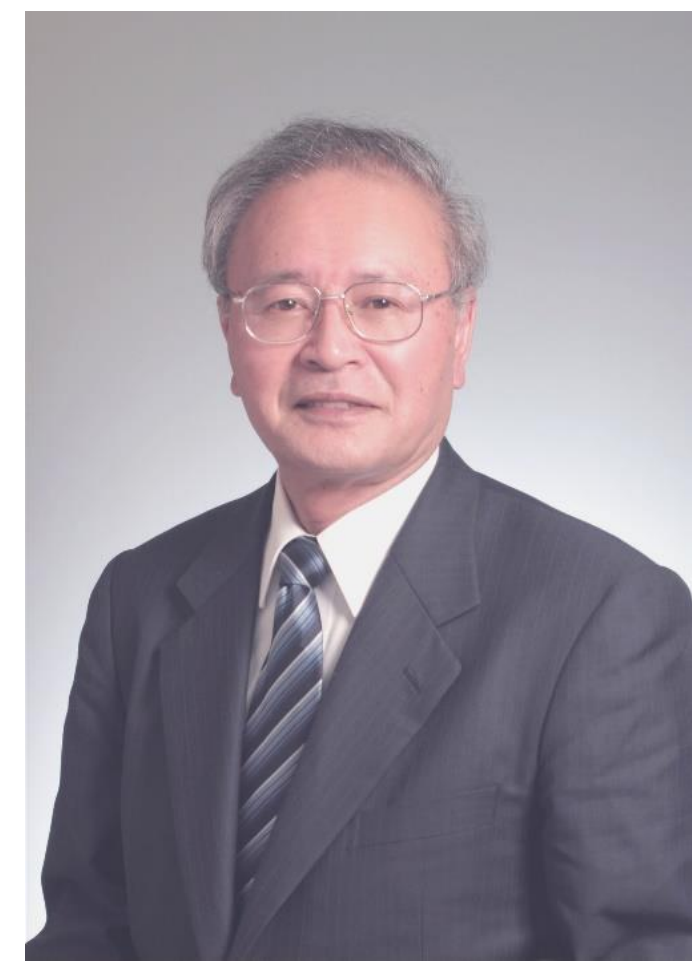

Prof. Hitoshi Emi

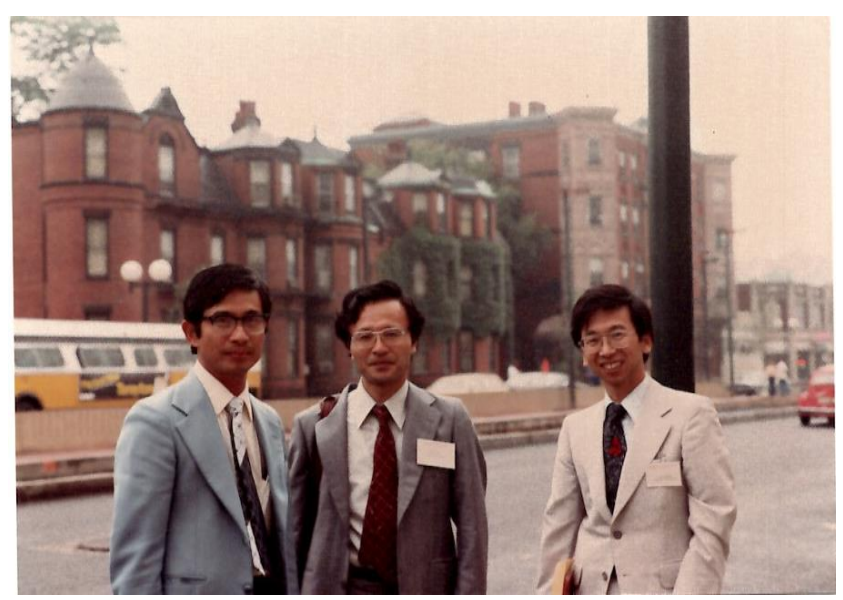

Prof. Hitoshi Emi (middle) photographed with Prof. Chiu-sen Wang (left) and Prof. Kikuo Okuyama (right). 
his research colleagues established the Japan Association of Aerosol Science and Technology (JAAST) in 1983. The $1^{\text {st }}$ president of JAAST was Prof. Koichi Iinoya, Prof. Emi was the first editor-in-Chief of the Journal of Aerosol Research in Japan, which was the only scientific journal in Japan specializing in aerosol at that time. He served as the editorin-chief for eight years and established a firm ground for the journal. Later he became president of JAAST and strengthened the ties between academia and industry in the field of aerosol science and technology. He also served as vice president of the Society of Chemical Engineering, Japan, President of the Association of Powder Process Industry and Engineering, Japan. Along with the important positions in academic societies, he devoted himself to education and fostered many aerosol researchers including many of us. He taught us that research in academia should be fundamental and that there was a lot to learn from abroad in order to level up research in Japan. He also taught us to conduct fundamental research which is attractive to industry and carry out collaboration.

Prof. Emi will be remembered as the one who opened the door of aerosol research in Japan and continued in developing aerosol research. Upon retiring he kept his interest and continued his studies so that he could give us advice should we, his colleagues, ask. His contribution to the development of aerosols and filtration has been tremendous. His lifetime dedication to research and helping students is something that we as his successors must carry out too. We are very honored and proud that we were able to learn from him and to be counted as his successors as well as his friends. Rest in peace Prof Emi knowing that we will continue in your footsteps. 